\title{
Obesity: The Gateway to III Health - an EASO Position Statement on a Rising Public Health, Clinical and Scientific Challenge in Europe
}

\author{
Gema Frühbeck $^{a}$ Hermann Toplak $^{b}$ Euan Woodward ${ }^{c}$ \\ Volkan Yumuk $^{d}$ Max Maislos ${ }^{e}$ Jean-Michel Oppert ${ }^{f}$ for the Executive \\ Committee of the European Association for the Study of Obesity \\ aDepartment of Endocrinology and Nutrition, Clínica Univ. de Navarra, University of \\ Navarra, CIBERobn, Instituto de Salud Carlos III, Pamplona, Spain, b Department of Internal \\ Medicine, Universitäts-Klinik für Innere Medizin, Graz, Austria, ' European Association for \\ the Study of Obesity, London, UK, dDivision of Endocrinology, Metabolism and Diabetes, \\ Istanbul University Cerrahpasa Medical Faculty, Istanbul, Turkey, ${ }^{\mathrm{e}}$ Atherosclerosis and \\ Metabolism Unit, Soroka UMC, Ben-Gurion University SHC, Beer Sheva, Israel, ${ }^{f}$ Department \\ of Nutrition, Pitie-Salpetriere Hospital; Institute of Cardiometabolism and Nutrition (ICAN), \\ University Pierre et Marie Curie, Paris, France
}

\section{Obesity: A Global and European Burden}

Although obesity was only introduced in the 1950s into the International Classification of Diseases (currently ICD-10 code E66, though EASO thinks that this categorization requires revision and is committed to propose novel criteria for ICD-11), it had already reached epidemic proportions by the end of the century, becoming one of the leading causes of death and disability worldwide. According to the World Health Organization (WHO) the prevalence of obesity has tripled since the 1980s in many countries of the WHO European Region, with overweight and obesity affecting $50 \%$ of the population in the majority of European countries [1]. In 2008, 1.5 billion adults, 20 years and older, were overweight with an estimated 500 million adults worldwide being obese (over 200 million men and nearly 300 million women); approximately $65 \%$ of the world's population inhabit countries where overweight and obesity kill more people than underweight [2,3]. The figures of affected individuals rage on unabated, and more than 40 million children under the age of 5 years were overweight in 2010 [3]. Noteworthy, severe obesity (i.e., a BMI $>35 \mathrm{~kg} / \mathrm{m}^{2}$ ) is a rapidly growing segment of the obesity epidemic in which the detrimental effects are particularly evident and harsh. Moreover, obesity not only disproportionately affects the disadvantaged segments of the population, but these groups experience the most important increases in obesity prevalence. Thus, the WHO has declared obesity as the largest global chronic health problem in adults, which is emerging 
Frühbeck et al.: Obesity: The Gateway to Ill Health - an EASO Position Statement on a Rising Public Health, Clinical and Scientific Challenge in Europe

as a more serious world health problem than malnutrition. In fact, obesity has become a truly global problem that has led to coin the term 'globesity' to describe the escalating global pandemia affecting both developed and developing countries [2]. In this sense, it has been estimated that $60 \%$ of the world's population, i.e., 3.3 billion people, could be overweight $(2.2$ billion) or obese (1.1 billion) by 2030 if recent trends continue [4]. In spite of these preoccupying facts, obesity is frequently not even thought of as a frequent, serious, complex and chronic disease and is often even dismissed or neglected as a clinical entity.

\section{The Health Risks of Obesity}

Regrettably, the consequences of obesity are more far-reaching than mere aesthetic problems and heavily impact both directly and indirectly on a broad range of aspects of health, expanding from single individuals up to whole nations. The WHO highlights that obesity is responsible for $10-13 \%$ of deaths in different parts of the world [1]. Although a BMI above $30 \mathrm{~kg} / \mathrm{m}^{2}$ has been shown to increase the risk of death from heart disease, stroke, and some cancers, the questions about the strength of the relationship between high BMI and allcause mortality as well as the optimal BMI in relation to mortality are still discussed [5, 6]. A recent meta-analysis looking at all-cause mortality spanning nearly 3 million people (and comprising 270,000 deaths) provided clear evidence that, relative to normal weight, both all grades of obesity (i.e., a BMI $>30 \mathrm{~kg} / \mathrm{m}^{2}$ ) and grade 2 and 3 obesity (i.e., a BMI $35-40 \mathrm{~kg} / \mathrm{m}^{2}$ and $>40 \mathrm{~kg} / \mathrm{m}^{2}$, respectively) were associated with significantly higher all-cause mortality [6]. However, grade 1 obesity (i.e., a BMI $30-35 \mathrm{~kg} / \mathrm{m}^{2}$ ) overall was not associated with higher mortality, and overweight (i.e., a BMI $25-30 \mathrm{~kg} / \mathrm{m}^{2}$ ) was reportedly associated with significantly lower all-cause mortality. These latter findings were not in line with those of a prior systematic analysis comprising 1.46 million white adults and over 160,000 deaths [5], including pooled data from 19 prospective studies adjusted for age, study, physical activity, alcohol consumption, education, and marital status, in which, overall for men and women combined, for every 5-unit increase in BMI, a 31\% increase in risk of death was observed, with all-cause mortality being generally lowest with a BMI of $20.0-24.9 \mathrm{~kg} / \mathrm{m}^{2}$. Among others, the controversies between both extensive studies may well be the result of methodological challenges of applying different BMI categories for the normal-weight comparison as well as the limitations of the BMI in reflecting real body fat content and distribution [7]. Whatever discussions are arising from these data, the evidence altogether emphasizes the deleterious health consequences of severe obesity (i.e., BMI $>35 \mathrm{~kg} / \mathrm{m}^{2}$ ) which is indeed associated with increased all-cause mortality.

While a more precise BMI cut-off value or a better indicator of unhealthy body composition is identified, it is worth considering that the Global Burden of Disease Study 2010 (GBD), a multi-investigator collaboration for global comparative descriptive epidemiology, concluded that in the time period from 1990 to 2010 the GBD continued to shift away from communicable to non-communicable diseases (NCDs) and from premature death to disabilityadjusted life years (DALYs) [8]. Dietary risk factors and physical inactivity collectively accounted for $10 \%$ of global DALYs in 2010 [9]. Not surprisingly, the comparison of risk factors during those decades showed that several dietary risks factors had moved up the rankings with the most prominent one being diets low in fruits [10]. Excess weight drastically augments a person's risk of developing a number of NCDs, like cardiovascular disease, diabetes and cancer, at the same time as causing diverse psycho-social problems and various physical disabilities. The WHO emphasizes that $44 \%$ of the diabetes burden, $23 \%$ of the ischaemic heart disease burden and around $7-41 \%$ of certain cancer burdens are attributable to overweight and obesity [3]. In the majority of European countries, overweight and obesity 
Frühbeck et al.: Obesity: The Gateway to Ill Health - an EASO Position Statement on a Rising Public Health, Clinical and Scientific Challenge in Europe

are responsible for about $80 \%$ of cases of type 2 diabetes, $35 \%$ of ischaemic heart disease and $55 \%$ of hypertensive disease among adults [11]. Moreover, the risk of developing more than one of these co-morbidities also increases when body weight is elevated. Noteworthy, excess body weight also puts patients at a higher risk of hypertension, dyslipidaemia, stroke, sleep apnoea, and other serious co-morbidities. In addition, a range of debilitating conditions such as osteoarthritis, respiratory difficulties, gallbladder disease, infertility, and psycho-social problems, which lead to reduced life expectancy, quality of life and disability, are extremely costly in terms of both absence from work and use of health resources $[1,12,13]$. Importantly, while until now life expectancy rates had continuously increased in the USA despite the obesity epidemic, a recent study shows that particularly among uneducated females life expectancy has actually decreased, with obesity likely representing one of the underlying reasons [14].

\section{Time for Action versus Complacency}

Although overweight and obesity are considered the 5th leading risk for global deaths according to the WHO [3], clear opportunities for diagnosis and, consequently, treatment are being missed [15]. Since obesity truly is a 'gateway' to so many other disease areas, it will block, if appropriately managed and prevented, a major supply route to ill health [16]. Obesity should be viewed as one of the main targets for current efforts to combat the increasing NCDs epidemic [17]. As a harbinger of a multitude of disabling and fatal diseases, obesity represents one of the most relevant public health challenges of the 21st century, threatening to reverse many of the health gains achieved so far. We already lost the battle of halting the epidemic in the past century [18]. In order to curb this situation, obesity should be a top priority, with increased commitment for concerted, coordinated and specific actions. It is clearly imperative that obesity is targeted as an area for immediate action and priority. A comprehensive and pro-active strategy to deal with the challenges posed by the obesity epidemic in a sustainable way is urgently needed. Encouraging the instauration and implementation of programmes for early competent diagnosis, treatment and prevention is mandatory. Obesity is a serious, chronic disease that will only worsen without thoughtful and evidence-based interventions that address both individual citizens and the environmental context they live in. It is clearly imperative that obesity is targeted as an area for immediate action and priority for research, innovation and action at European level.

\section{Disclosure Statement}

The authors declared no conflict of interest.

\section{References}

1 World Health Organization: Obesity. www.euro.who.int/en/what-we-do/health-topics/noncommunicablediseases/obesity.

-2 Finucane MM, Stevens GA, Cowan MJ, Danaei G, Lin JK, Paciorek CJ, Singh GM, Gutierrez HR, Lu Y, Bahalim AN, Farzadfar F, Riley LM, Ezzati M; Global Burden of Metabolic Risk Factors of Chronic Diseases Collaborating Group (Body Mass Index): National, regional, and global trends in body-mass index since 1980:systematic analysis of health examination surveys and epidemiological studies with 960 country-years and 9.1 million participants. Lancet 2011;377:557-567.

3 World Health Organization: Fact Sheet No.311 (May 2012). www.who.int/mediacentre/factsheets/fs311/en/.

4 Kelly T, Yang W, Chen CS, Reynolds K, He J: Global burden of obesity in 2005 and projections to 2030. Int J Obes (Lond) 2008;32:1431-1437. 
Frühbeck et al.: Obesity: The Gateway to Ill Health - an EASO Position Statement on a Rising Public Health, Clinical and Scientific Challenge in Europe

5 Berrington de Gonzalez A, Hartge P, Cerhan JR, Flint AJ, Hannan L, MacInnis RJ, Moore SC, Tobias GS, AntonCulver H, Freeman LB, Beeson WL, Clipp SL, English DR, Folsom AR, Freedman DM, Giles G, Hakansson N, Henderson KD, Hoffman-Bolton J, Hoppin JA, Koenig KL, Lee IM, Linet MS, Park Y, Pocobelli G, Schatzkin A, Sesso HD, Weiderpass E, Willcox BJ, Wolk A, Zeleniuch-Jacquotte A, Willett WC, Thun MJ: Body-mass index and mortality among 1.46 million white adults. N Engl J Med 2010;363:2211-2219.

-6 Flegal KM, Kit BK, Orpana H, Graubard BI: Association of all-cause mortality with overweight and obesity using standard body mass index categories: a systematic review and meta-analysis. JAMA 2013;309:71-82.

7 Heymsfield SB, Cefalu WT: Does body mass index adequately convey a patient's mortality risk? JAMA 2013; 309:87-88.

8 Murray CJ, Vos T, Lozano R, Naghavi M,et al: Disability-adjusted life years (DALYs) for 291 diseases and injuries in 21 regions, 1990-2010:a systematic analysis for the Global Burden of Disease Study 2010. Lancet 2012;380:2197-2223.

-9 Lim SS, Vos T, Flaxman AD, et al: A comparative risk assessment of burden of disease and injury attributable to 67 risk factors and risk factor clusters in 21 regions, 1990-2010:a systematic analysis for the Global Burden of Disease Study 2010. Lancet 2012;380:2224-2260.

10 Watts C, Cairncross S: Should the GBD risk factor rankings be used to guide policy? Lancet 2012;380:20602061.

11 Tsigos C, Hainer V, Basdevant A, Finer N, Mathus-Vliegen E, Micic D, Maislos M, Roman G, Schutz Y, Toplak H, Yumuk V, Zahorska-Markiewicz B; Obesity Management Task Force of the European Association for the Study of Obesity: Criteria for EASO-collaborating centres for obesity management. Obes Facts 2011;4:329-333.

$\$ 12$ Finkelstein EA, Trogdon JG, Cohen JW, Dietz W: Annual medical spending attributable to obesity: payer- and service-specific estimates. Health Aff (Millwood) 2009;28:w822-w831.

13 Clark H: NCDs: a challenge to sustainable human development. Lancet 2013;381:510-511.

-14 Olshansky SJ, Antonucci T, Berkman L, Binstock RH, Boersch-Supan A, Cacioppo JT, Carnes BA, Carstensen LL, Fried LP, Goldman DP, Jackson J, Kohli M, Rother J, Zheng Y, Rowe J: Differences in life expectancy due to race and educational differences are widening, and many may not catch up. Health Aff (Millwood) 2012;31:18031813.

15 Frühbeck G: Obesity: screening for the evident in obesity. Nat Rev Endocrinol 2012;8:570-572.

16 European Association for the Study of Obesity Executive Summary of the European Obesity Research Conference: From Biology to Society - what Message Can Obesity Research Deliver to Policy Makers? Brussels, February 29, 2012. www.easo.org/images/EASO\%20Research\%20Conference\%20-\%200utcomes\%20 Summary.pdf.

17 Beaglehole R, Bonita R, Horton R, Adams C, Alleyne G, Asaria P, Baugh V, Bekedam H, Billo N, Casswell S, Cecchini M, Colagiuri R, Colagiuri S, Collins T, Ebrahim S, Engelgau M, Galea G, Gaziano T, Geneau R, Haines A, Hospedales J, Jha P, Keeling A, Leeder S, Lincoln P, McKee M, Mackay J, Magnusson R, Moodie R, Mwatsama M, Nishtar S, Norrving B, Patterson D, Piot P, Ralston J, Rani M, Reddy KS, Sassi F, Sheron N, Stuckler D, Suh I, Torode J, Varghese C, Watt J; Lancet NCD Action Group; NCD Alliance: Priority actions for the non-communicable disease crisis. Lancet 2011;377:1438-1447.

18 Frühbeck G: Is Europe really battling obesity? Obes Facts 2010;3:219-221. 